\title{
Energy used by transport systems in India: the role of the urban population, sources, alternative modes and quantitative analyses
}

\author{
I. Pinna ${ }^{1}$, B. Dalla Chiara ${ }^{1} \&$ K. Pant P $^{2,3}$ \\ ${ }^{I}$ Politecnico di Torino, Italy \\ ${ }^{2}$ IIT-Bombay, India \\ ${ }^{3}$ Politecnico di Torino, Italy
}

\begin{abstract}
The purpose of this work is to at first give a general overview of the state-of-the-art transportation system in India, outlining the related energy consumption for different modes of transport; trains, light trucks, heavy trucks, buses, three wheelers, two wheelers, cars and jeeps, with their consequent estimated emissions.

These elements are essential for the preparation of high-level strategic transport planning for the issue of energy as a whole, to help India make the right choices for the most suitable transportation systems. A relevant consideration at the base of this work is the high urbanization and motorization level in Indian metropolises in the last years. In order to provide an appropriate analysis on energy consumption, that is fully satisfactory from a methodological viewpoint and related to all transport systems, the well-to-wheel WTW index was adopted, taking into account that, especially in the urban context, that shorter journeys would easily be addressed by electric traction, while this is not taken for granted at all, according to the overall energy chain consumption and specific considerations on energy available in India when compared to Europe, which are included.

Pursuing a WTW global index for India, that takes into account both the energy and environmental aspects on a uniform basis, is an important aim. It allows the best choices to be made as well as enabling the comparison between some of the most important means of transport, powertrain and fuel options on the Indian market, mainly the urban one.
\end{abstract}


In this paper we ascertain the quantity of energy consumed and the pollutants emitted by the different transportation modes (road, rail, air) carrying freight between Delhi and Mumbai, the two metropolitan cities of India.

Keywords: India, transportation system, estimated emissions, urbanization, well to wheel analysis.

\section{Introduction}

In developing economies like India, increased economic activity leads to growing income per capita; as standards of living rise and the demand for personal transportation increases, from a non-motorised mobility to a motorised one. The European experience is useful for pursuing the correct choices in the transport domain for as far as possible.

From the energy supply viewpoint, uncertainty about the present and future availability and security of oil supplies, the prospect of rising oil prices and environmental concerns about emissions are the major challenges.

Market forces and government policies could drive the development of highly efficient vehicle technologies and of the transport systems itself, with the potential to alter future demand for transportation fuels, reduce emissions, improve energy security and provide significant energy savings. Widespread adoption of alternative vehicle and transport technologies, combined with expansion of mass transit infrastructure and personal mobility, could be an attractive option for long term development of the whole transportation sector.

\section{Urban population and registered motor vehicles in India}

India is the second most populous country in the world, with over 1.21 billion people - according to the census of 2011, more than a sixth of the world's population. India is projected to become the world's most populous country by 2025, surpassing China, according to present trends and projections.

The level of urbanization, i.e. inhabitants living in urban areas, has increased from $27.81 \%$ in 2001 to $31.16 \%$ in 2011 . Migration to major cities caused rapid increase in urban population. According to some documents by the United Nations and the International Energy Agency, India will probably witness the largest increase in urban population in the next four decades followed by China [1].

In India, personalised motorised mobility, satisfied mainly by two wheelers and passenger cars, accounted for more than four-fifth of the motor vehicle population. Two-wheelers account for about $72 \%$, followed by passenger cars at $13.3 \%$ and other vehicles at $8.4 \%$.

At lower levels of income, 2-wheelers are an affordable and cost effective means of personalised mobility. In contrast to personalised mode, the share of buses in total registered vehicles has declined from $11.1 \%$ in 1951 to a mere $1.3 \%$ in 2009 . The erosion of share of buses in the vehicle population reflects slow growth in public passenger bus transport services. 
With a rising income and greater need for motorised mobility, the personalised mode of transport is likely to grow in importance in the coming years. The chart in Figure 1 indicates that the share of 2-wheeler population shows a steep rise [2].

The total registered vehicles in the country grew at a Compound Annual Growth Rate (CAGR) of $9.8 \%$ between 1991 and 2009. Two wheelers and cars grew at a CAGR $10.3 \%$ and $9.6 \%$ respectively, which was higher if compared to the growth in buses $(8.7 \%)$ (Table 1) [3-5].

The growth of vehicular traffic on roads has been far greater than the growth in the road network and as a result, the main arterial roads in the country are facing capacity saturation (Figure 2 ) $[4,5]$.

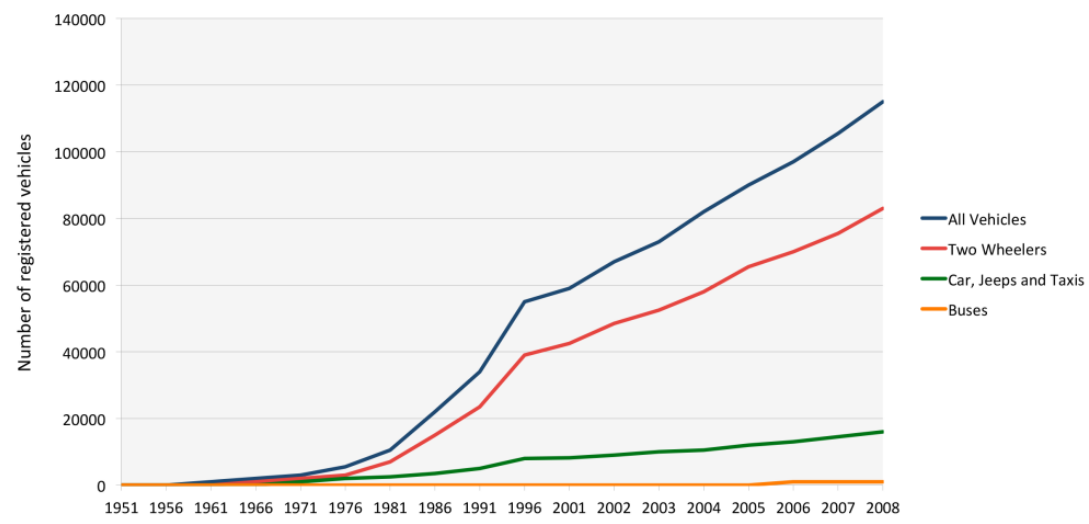

Figure 1: $\quad$ Growth of the number of registered vehicles over the years in India.

Table 1: Compound annual growth rates (in \%) in vehicles and road extension or length.

\begin{tabular}{|c|c|c|c|c|c|c|c|c|c|c|c|c|}
\hline & \multicolumn{6}{|c|}{ Vehicles } & \multicolumn{6}{|c|}{ Roads } \\
\hline Period & 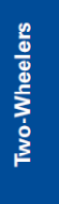 & 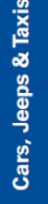 & 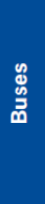 & 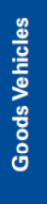 & 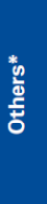 & $\begin{array}{l}\bar{\Phi} \\
\text { है }\end{array}$ & $\frac{n}{2}$ & $\begin{array}{l}\frac{\rho}{3} \\
\frac{2}{2} \\
\infty \\
\frac{\omega}{5} \\
\frac{1}{\omega}\end{array}$ & $\overline{\mathrm{g}}$ & 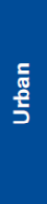 & 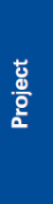 & $\begin{array}{l}\overline{\Phi ّ} \\
\text { Фै }\end{array}$ \\
\hline 2001/1991 & 10.5 & 9.1 & 6.7 & 8.1 & 8.6 & 9.9 & 5.5 & 3.1 & 1.4 & 3 & 0.6 & 2.1 \\
\hline 2007/1991 & 10.4 & 9.5 & 9.2 & 8.7 & 7.8 & 9.9 & 4.4 & 2.8 & 4.1 & 3 & 1.6 & 3.5 \\
\hline 2008/1991 & 10.3 & 9.6 & 9 & 8.7 & 7.8 & 9.8 & 4.1 & 2.8 & 4 & 2.9 & 1.5 & 3.4 \\
\hline 2009/1991 & 10.3 & 9.6 & 8.7 & 8.7 & 7.7 & 9.8 & NA & NA & NA & NA & NA & NA \\
\hline
\end{tabular}




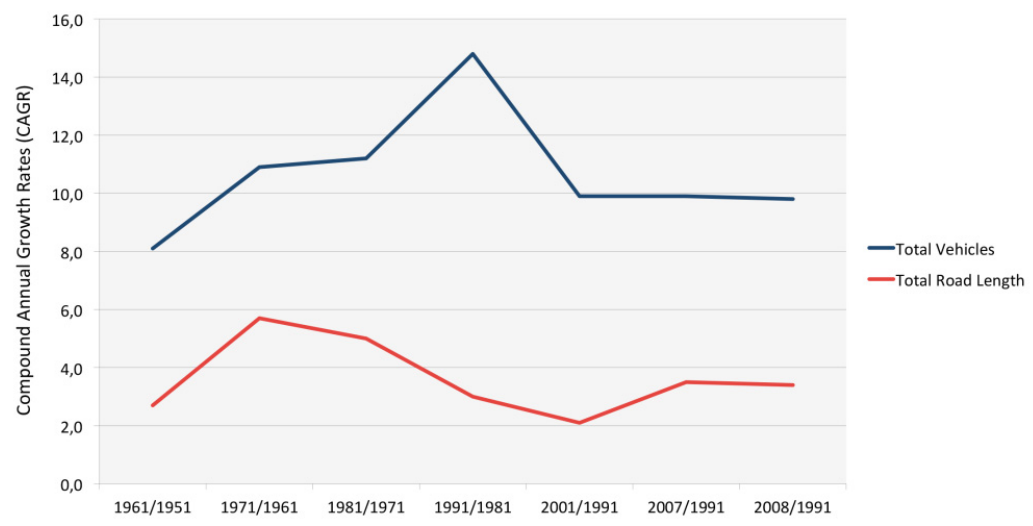

Figure 2: Graph of compound annual growth rate of vehicles and road extension (length) over the years.

The reasons for this are:

a. Focus on the growth of the National Highway network though with lack of maintenance of arterial roads;

b. Introduction of small and cheap cars, like Nano car from Tata Group, which are rising rapidly in the Indian market. Sales data [6, 7] show that total vehicle sales increased by an annual average rate of $15 \%$ over the last 5 years.

\subsection{Effect of GDP}

Transport sector accounted for a share of $6.6 \%$ in India's Gross Domestic Product (GDP) in 2008-09, with road transport being the dominant mode of transport, with a share of 4.8 per cent in GDP.

It may be noted how the entire increase in the percentage share of transport in GDP since 1999-2000 has come from the road transport sector only, with a share of other modes remaining either constant or falling marginally.

The total air passenger traffic in India has increased from 109 million in $2008-09$ to 143 million in $2010-11$, a $31 \%$ increase in 3 years, international $20 \%$ and domestic $37 \%$, but its contribution to India's economy is negligible.

\subsection{Transport by mode}

Walking to work remains the prevailing mode of transport for Indian households today. Car ownership is still very low in India but sales of cars are starting to increase rapidly. Not surprisingly, bicycles are the most widely used vehicle type owned by households. Traveling by bus is by far the most used means of transport in India, accounting for $56 \%$ of total passenger-km. This results from a high passenger load factor in bus transport. 
The passenger-km in India has increased from 1,327 billion passengerkilometres (BPkm) to 2,933 BPkm between 1990 and 2004, at an average annual growth rate of $5.9 \%$. Overall road transport is the fastest growing mode of transportation with an annual growth rate of $6.4 \%$, followed by air at $6.2 \%$ and rail by $3.6 \%$.

Road dominated overall passenger transport with a share of $75 \%$ in 1990 and $81 \%$ in 2004 .

Although transport by rail has also increased, its share has decreased from $24 \%$ to $18 \%$ during the last 14 years, due to intense competition from road transport. Operational inefficiencies and capacity constraints on key routes have also played a role in the slow growth of India's rail traffic (WB, 2002). Although a large proportion of passenger motorised mobility (in terms of passenger-km) is still catered to by buses, the share of bus use has decreased from $61 \%$ to $55 \%$. The use of cars has increased from $2 \%$ to $6 \%$, two wheelers from $9 \%$ to $15 \%$, and auto-rickshaws from $3 \%$ to $5 \%$. The share of transport by waterways is small compared to other modes.

Tonne-km was estimated to be equal to 610 billion in 2004, with an increase of $3.1 \%$ annually over the period 1990-2004. Rail transport represented 58\% of tonne-km in 2004, down from $64 \%$ in 1990 , medium and heavy trucks represent $37 \%$, while light commercial vehicles represent a constant share of $4 \%$ (Figure 4 ).

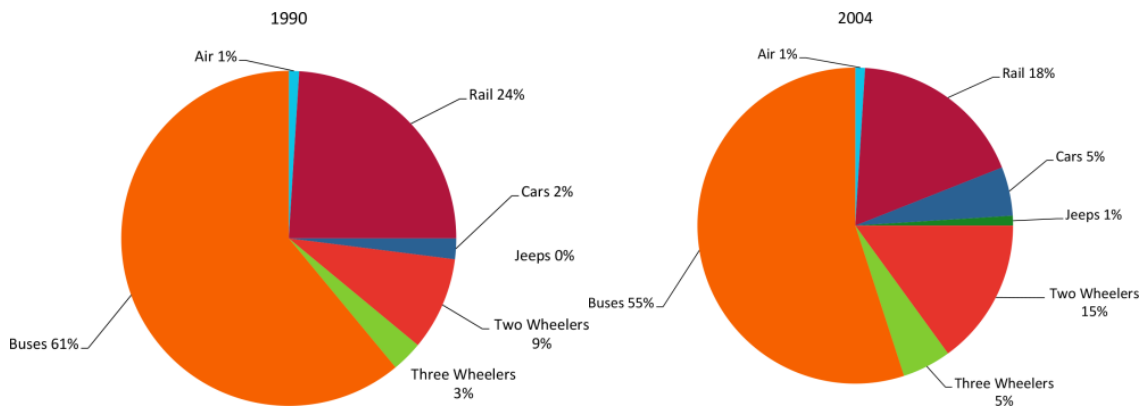

Figure 3: $\quad$ Passenger-km in transport modes, India.

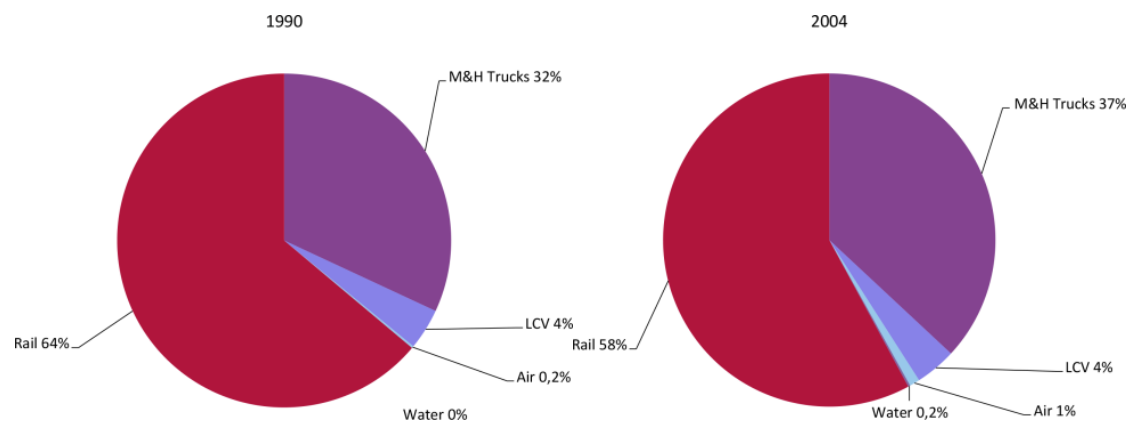

Figure 4: $\quad$ Freight tonne-km per mode. 


\section{Transport and energy}

Transport and energy are closely related. Energy is nowadays a crucial constraint on transport and transport is a major determinant of energy demand.

India's commercial energy resource base is meagre compared with the population; while India has a sixth of the world's population, it accounts for only about $0.8 \%$ of total geological reserves, with $5.7 \%$ of world's proven coal reserves, and $0.4 \%$ of the world's proven hydrocarbon reserves. According to present trends, India's transportation energy use is projected to grow at the fastest rate in the world, averaging 5.5\%, compared with the world average of $1.4 \%$ per year. India is increasingly dependent on imported petroleum.

While India's dependence on imported petroleum is growing towards uncomfortable levels, its energy usage efficiency in the transport sector is estimated to be only half that in the industrialised countries. In the transport sector, based on existing estimates in 1996-97, 85\% of oil use is in the road sector where energy- inefficient designs, poor vehicle maintenance and inadequate and low-grade roads are widely prevalent.

Energy conservation, substitution of imported by domestic fuels and the pursuit of transportation policies have to become vital national concerns.

\subsection{Gasoline and diesel transport consumption}

In 2004, diesel and motor gasoline represented $90 \%$ of final energy consumed in the transport sector, while jet kerosene represented $8 \%$ and electricity $2 \%$. Diesel is the most used form of energy, with a share of $66 \%$, and motor gasoline representing 24\%. Statistics of energy consumption over time from the Ministry of Oil and Gas show a steady increase of motor gasoline, however statistics for diesel consumption show uneven trends (Figure 5) [7].

\subsection{Energy projection in transportation sector}

Considering final energy consumption as the direct amount of energy consumed by end users while primary energy consumption including final consumption plus the energy that was necessary to produce and deliver electricity, in India, the factor primary on final energy is relatively high, i.e. 4.2, because of high transmission losses. In 2020, the transportation sector is projected to account for $21 \%$ of total final energy use and $14 \%$ of primary energy use, versus $16 \%$ of total final energy use and $12 \%$ of primary energy use in 2005 . This sector is expected to grow rapidly, with a projected annual growth rate of $6.8 \%$ for the period 2005 to 2020 .

Energy consumption from trucks is also expected to increase rapidly at $8.8 \%$ AAGR (average annual growth rate), followed by air transportation at $7.9 \%$. In terms of share, energy used by buses will decrease from a share of $20 \%$ to $8 \%$ while energy used by trucks, still representing the largest consumption, will grow from $28 \%$ to $38 \%$, and energy used by cars will increase from $10 \%$ to $18 \%$ (Figure 6). 


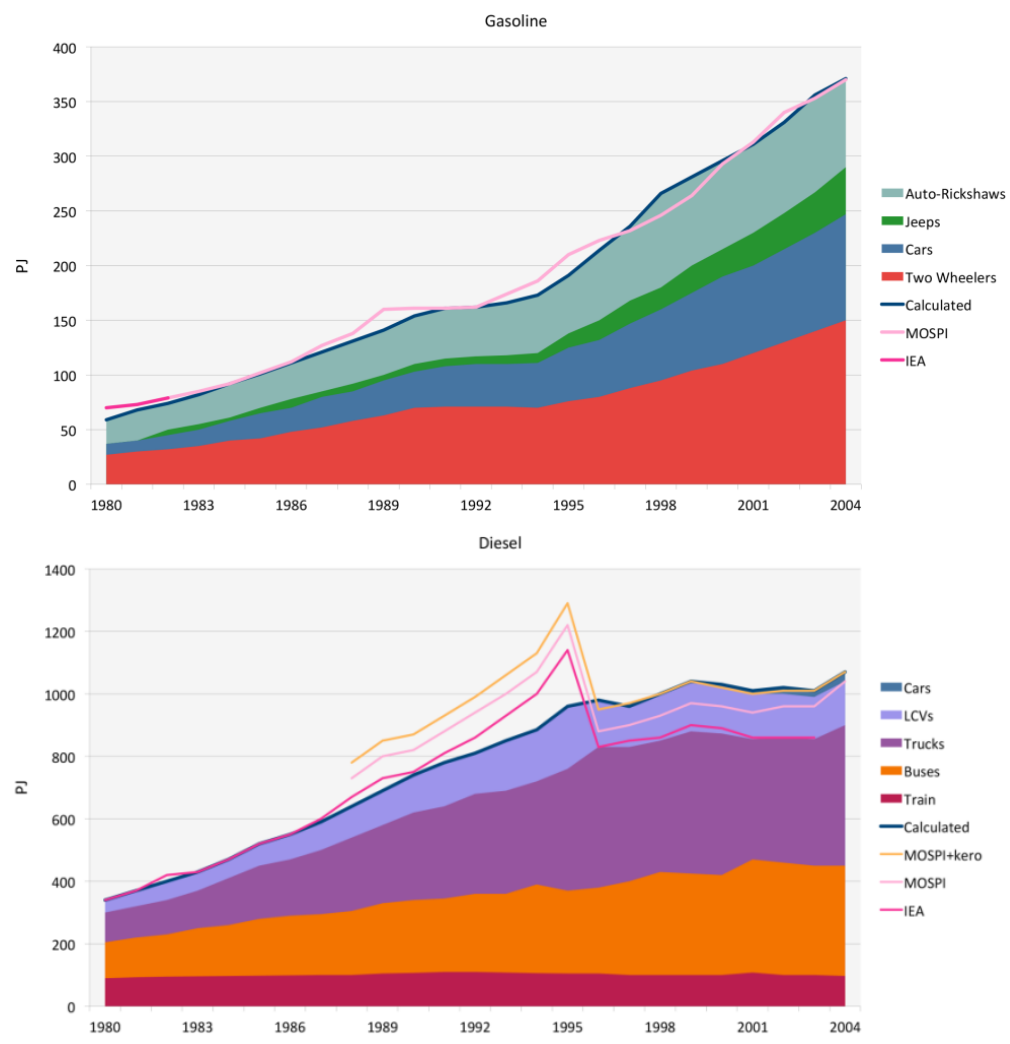

Figure 5: Gasoline and diesel usage over the years in India.

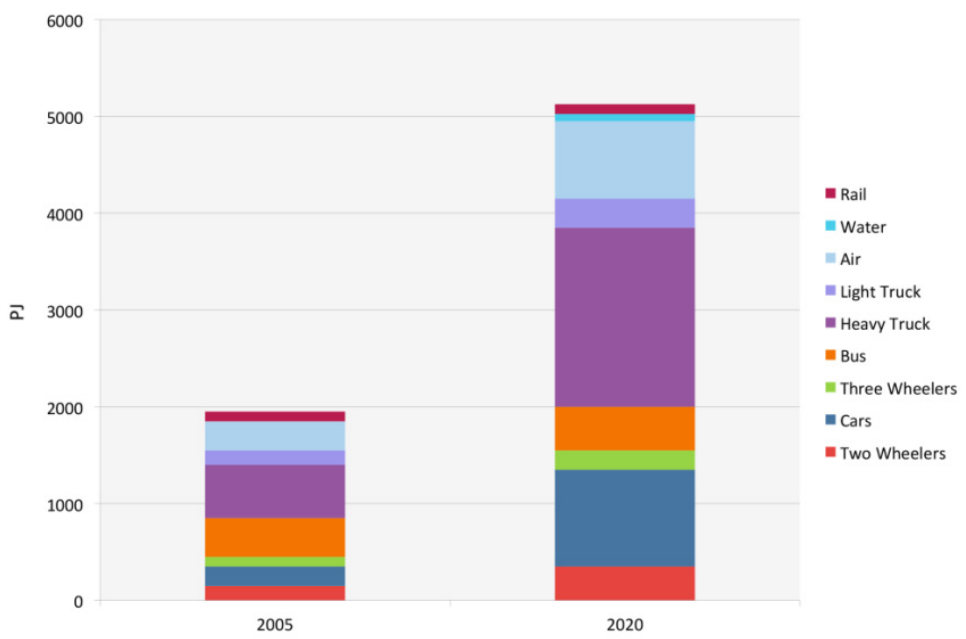

Figure 6: Energy use projection by mode and vehicle types, PJ. 
Two-wheelers make up about $63 \%$ of the projected vehicle stock, and yet they consume around 7\% of transport fuels (Figure 7). Concerning the type of fuel used, motor gasoline is expected to represent a slightly larger share of $23 \%$ compared to $21 \%$ in 2005 . Penetration of $\mathrm{CNG}$ is not visible here, because sufficient data were not available to estimate the energy use of this type of fuel.

However, in 1998, the Indian Supreme Court mandated compressed natural gas $(\mathrm{CNG})$ as the fuel for public transport in Delhi to control pollution. In 2002 a further ruling directed the Union government to give priority to the transport sector for $\mathrm{CNG}$. Yet more recent regulations gave a limit to the development or increase of the CNG use.

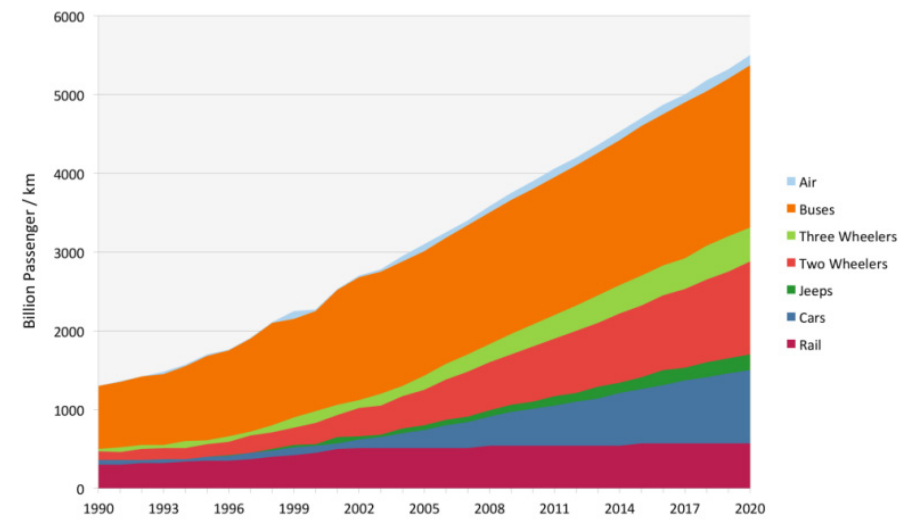

Figure 7: Passenger-km projections, India.

\section{Carbon dioxide emissions}

Two-thirds of world emissions for 2008 originated from just ten countries, with the shares of China and the United States far surpassing those of all others. Combined, these two countries alone produced $12.1 \mathrm{Gt} \mathrm{CO}_{2}$, about $41 \%$ of world $\mathrm{CO} 2$ emissions.

India, with $17 \%$ of world population, contributed less than $5 \%$ of the $\mathrm{CO}_{2}$ emissions (Figure 8), [8-10].

The WEO 2009 Reference Scenario projects that $\mathrm{CO}_{2}$ emissions in India will increase by more than 2.5 times by 2030 from 2008. A large share of these emissions is produced by the electricity and heat sector, which represented $56 \%$ of $\mathrm{CO}_{2}$ in 2008. The transport sector, which was only $9 \%$ of $\mathrm{CO}_{2}$ emissions in 2008 (Figure 9), is growing relatively slowly compared to other sectors of the economy [8-10].

Figure 10 reports the $\mathrm{CO}_{2}$ equivalent emission distribution from various modes of transport within the transport sector. 


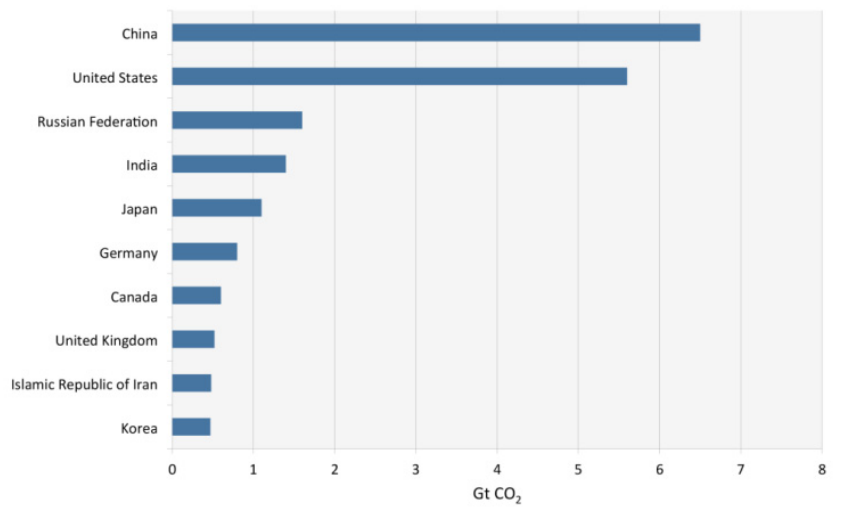

Figure 8: $\quad$ Top ten emitting countries in 2008.

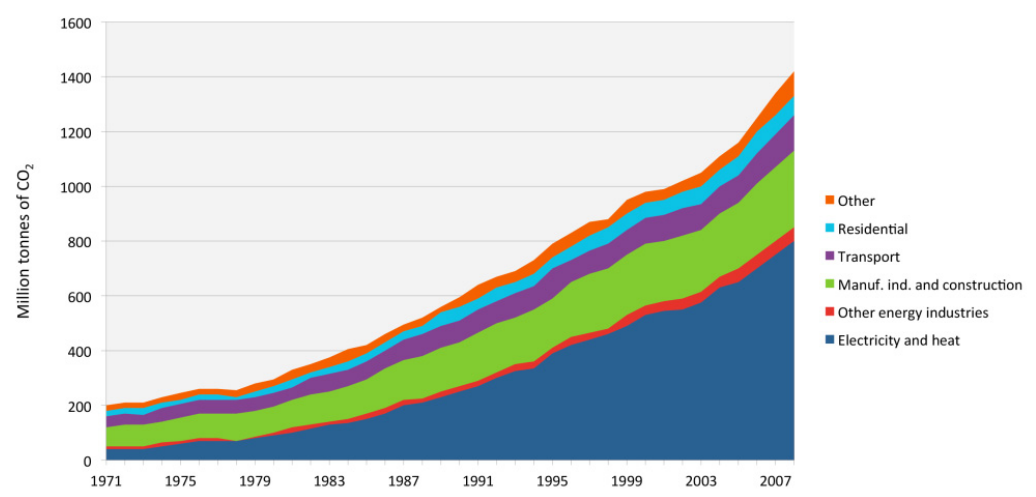

Figure 9: $\quad \mathrm{CO}_{2}$ emissions by sector in India.

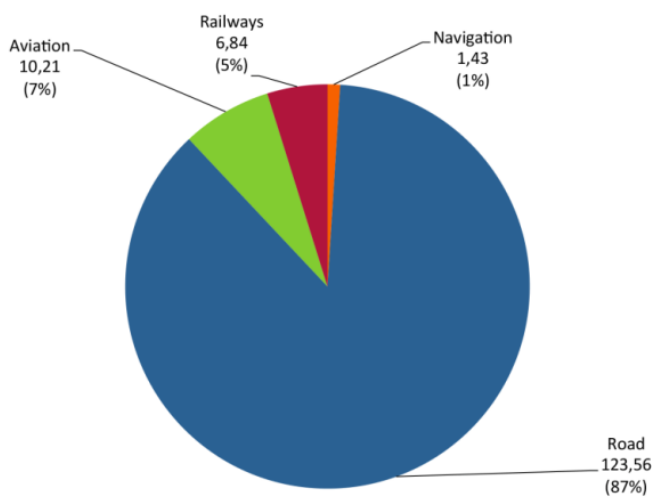

Figure 10: GHG (greenhouse gases) emissions from the Transport Sector. 


\section{Generation of electricity for transport systems}

Electricity is an energy vector which can be produced by a large variety of primary energy sources, both fossil fuels, renewables and nuclear.

In $2008,69 \%$ of electricity in India came from coal, another $10 \%$ from natural gas and 4\% from oil. The share of fossil fuels in the generation mix grew from $73 \%$ in 1990 to $85 \%$ in 2002 . The share of fossil fuels has declined steadily since then, falling to $81 \%$ in 2007 [8-10].

As regards to the use of electricity in vehicles, the use of electric motors proves to be highly efficient, nevertheless it remains to be analysed how the energy stored in their batteries is produced and/or distributed.

Electricity can be supplied to the motor either by direct link to the electricity grid (e.g. for trolley buses or trains) or it can be stored on board through batteries. For road transport the most common system used is through on board batteries; the system can work either as a pure battery electric vehicle or as a plug-in electric hybrid vehicle in combination with an internal combustion engine.

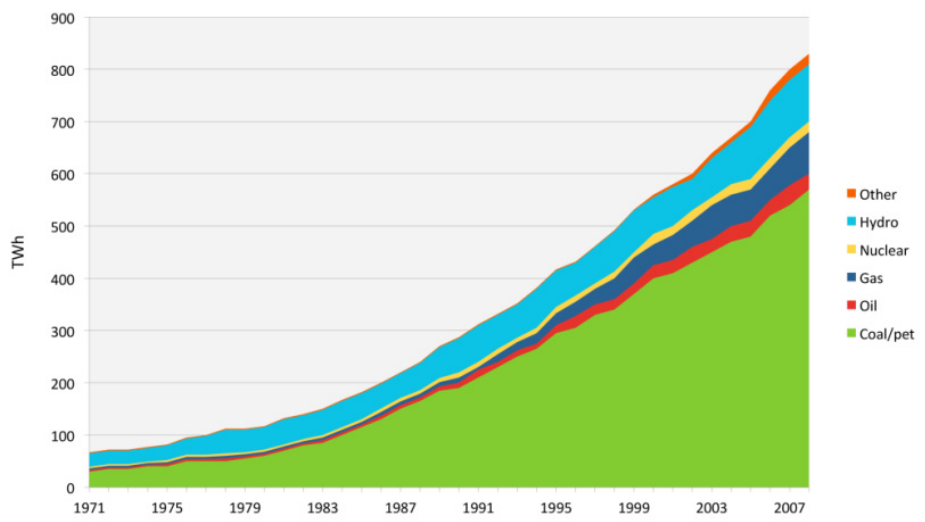

Figure 11: $\quad$ Electricity generation by fuel.

\section{Introduction to quantitative analyses: WTW}

According to previous consideration and the potential role of energy carriers in a highly growing urbanisation and motorisation as it is occurring in India, it is worthy to introduce a concept experienced in Europe, i.e. the WTW analysis. In order to provide an appropriate overall estimation on energy consumption, that is fully satisfactory from a methodological point of view and related to all transport systems, the WTW index needs to be adopted. We are dealing with a tool which was firstly proposed and consolidated in the automotive industry, but which is rarely applied to the other modes [11].

WTW is an absolute energy index whose function enables the comparison between combinations of different propulsion technologies and different fuels or 
energy carriers (i.e. hydrogen and electricity, which, once they are produced, can be considered as fuels), obtained from the most various primary sources.

The WTW index, which can be defined as the integration of all the processes required to produce and distribute a fuel (starting from the primary energy source) and use it in a vehicle (EC 2004), consists of the combination of two more specific sub-indexes, namely: well-to-tank (WTT) and tank-to-wheel (TTW).

As an applicative example, we found out the quantity of pollutants emitted by the different transportation modes (road, rail, air) carrying freight between Delhi and Mumbai, the two metropolitan cities of India. It is the busiest national highway of India. This has been done using EcoTransit website [12], a practical tool used by freight services and decision makers to compare the environmental impacts of different options. The calculation of energy consumption and emission data of a worldwide transport chain can be done rather quickly with the help of EcoTransIT World. As most of the heavy vehicles operating in India belong to Tata Motor Industries, which carry an average load of 20 tonnes, the data has been taken from Tata Motor Company.

The different transport modes and TTW/WTW have been differentiated by the following colours:
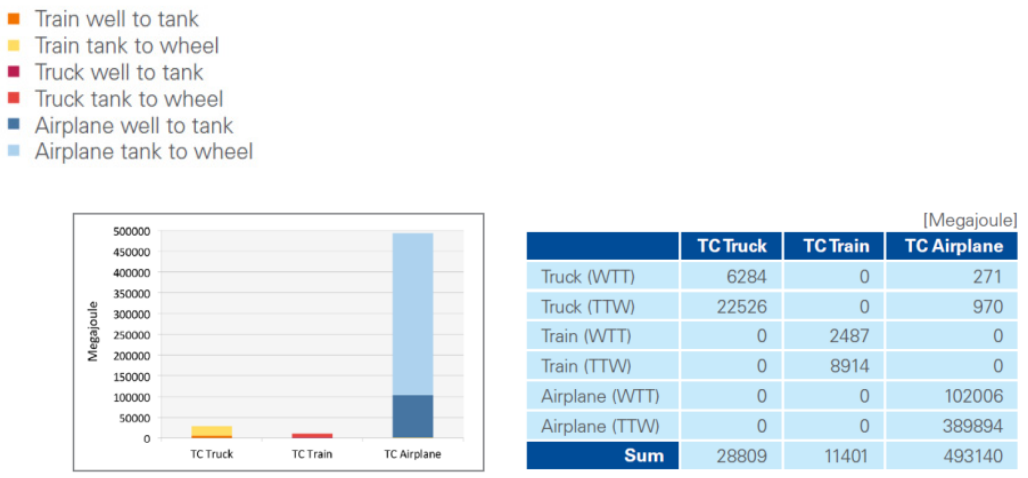

Figure 12: Primary energy consumption energy resource consumption.
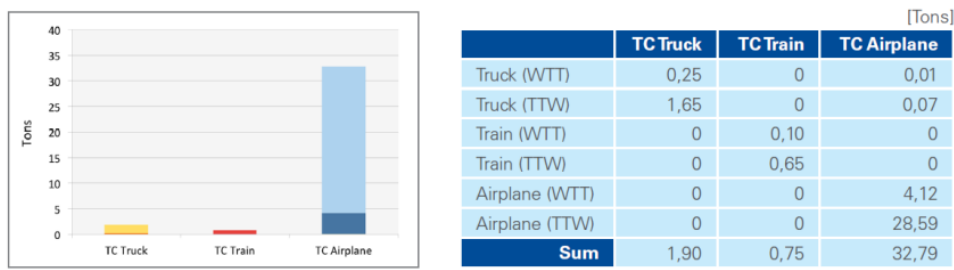

Figure 13: $\quad$ Carbon dioxide greenhouse gas, climate change. 


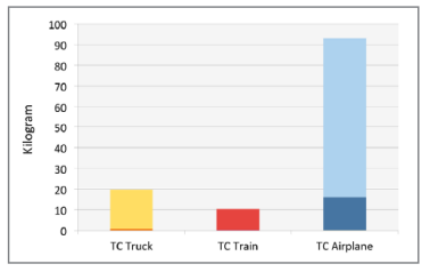

\begin{tabular}{|l|r|r|r|}
\hline & TC Truck & TC Train & TC Airplane \\
\hline Truck (WTT) & 0,97 & 0 & 0,04 \\
\hline Truck (TTW) & 18,76 & 0 & 0,18 \\
\hline Train (WTT) & 0 & 0,38 & 0 \\
\hline Train (TTW) & 0 & 10,04 & 0 \\
\hline Airplane (WTT) & 0 & 0 & 16,00 \\
\hline Airplane (TTW) & 0 & 0 & 76,88 \\
\hline Sum & 19,72 & 10,42 & 93,10 \\
\hline
\end{tabular}

Figure 14: Nitrogen Oxides, acidification, smog.

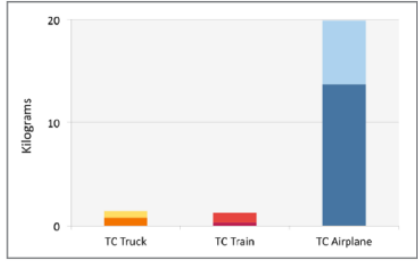

\begin{tabular}{|l|r|r|r|}
\hline & TC Truck & TC Train & TC Airplane \\
\hline Truck (WTT) & 0,793 & 0,000 & 0,034 \\
\hline Truck (TTW) & 0,636 & 0,000 & 0,002 \\
\hline Train (WTT) & 0,000 & 0,314 & 0,000 \\
\hline Train (TTW) & 0,000 & 0,945 & 0,000 \\
\hline Airplane (WTT) & 0,000 & 0,000 & 13,698 \\
\hline Airplane (TTW) & 0,000 & 0,000 & 6,157 \\
\hline Sum & 1,429 & 1,259 & 19,892 \\
\hline
\end{tabular}

Figure 15: Nonmethane Hydrocarbon smog, damage to health.
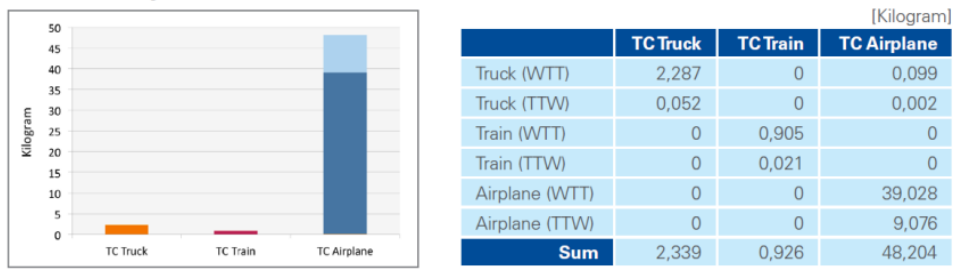

Figure 16: Sulphur Dioxide acidification, damage to health.

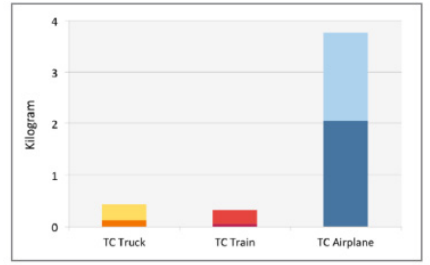

\begin{tabular}{|l|r|r|r|}
\hline & TC Truck & TC Train & TC Airplane \\
\hline Truck (WTT) & 0,124 & 0 & 0,005 \\
\hline Truck (TTW) & 0,307 & 0 & 0,002 \\
\hline Train (WTT) & 0 & 0,049 & 0 \\
\hline Train (TTW) & 0 & 0,276 & 0 \\
\hline Airplane (WTT) & 0 & 0 & 2,043 \\
\hline Airplane (TTW) & 0 & 0 & 1,716 \\
\hline Sum & 0,431 & 0,325 & 3,767 \\
\hline
\end{tabular}

Figure 17: $\quad$ Particulate matter combustion related.

The main issues of this study are:

- The pollutants emitted by air transportation are very high if compared to road and rail transportation, yet air transport does not require linear infrastructures, as roads and railways, just punctual ones (as airports).

- The rail transport implies an infrastructure, but, if well used, it is the most convenient option.

- The Government seems to impose public laws and policies based on the tank-to-wheel emissions, without taking into account the well-to-tank emissions. Therefore, Government policies should be based on the wellto-wheel emissions, i.e. the integration of WTT and TTW. 
As a matter of fact, not only a quantitative analysis has to be carried out but also the actual use of a transport mode in the urban context. In this view point, public transport is evidently favoured, especially rail, rope and metro systems from the independence from black oil viewpoint, yet it is at the same time obvious that the occupancy is a relevant factor too: if we compare consumption with occupancy, the following graph comes out [13].

It has been obtained from European experience, yet it can complete a synthetic overall analysis for a quantitative approach in facing actual motorisation and urbanisation problems of most Indian cities.

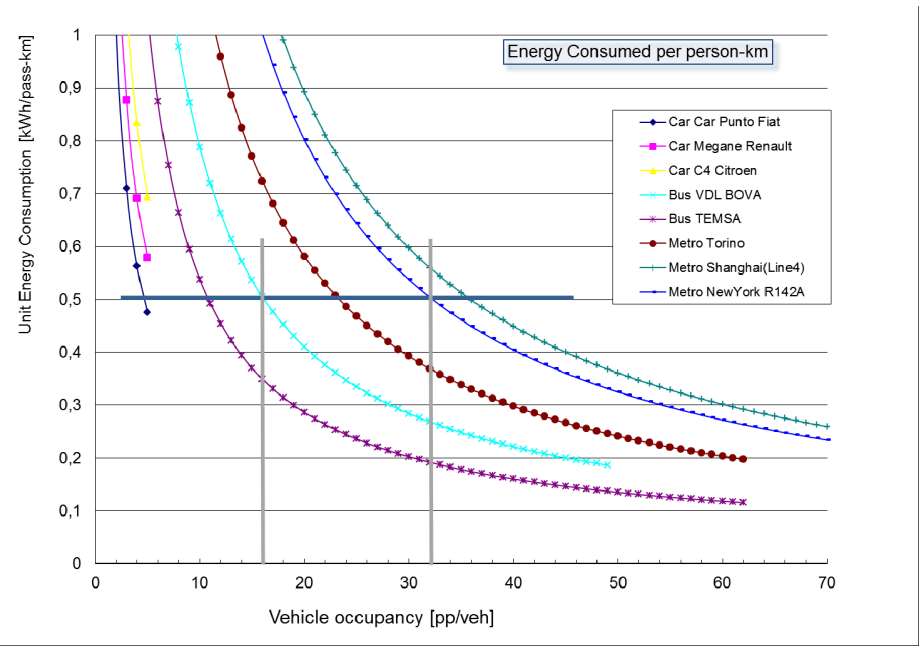

Figure 18: $\quad$ Energy consume per person-km.

\section{Conclusions}

We may synthesize the main results in the sentence: use of lower personal energy in motorised mobility in order to reduce the fuel consumption per person and consequent emissions. This aim can be pursued either through higher capacity transport modes, yet guaranteeing as far as possible vehicles loaded more than the break-even of energy, or with a low level of energy used for personal vehicles in movement (scooters, rickshaws, ...). The WTW analysis synthesises, in effect, most of this idea.

The other two main issues that emerge are:

- Inverse relationship between space and energy: provide more public space to more energy-efficient vehicles; segregated lanes for public transport, runways for bicycles, ITS (intelligent transport systems).

- $\quad$ LCC, life cycle cost, for any new infrastructure. 
The assignment of space to road transport should, at first, take into account the energy used by transport modes, possibly with a WTW analysis at the base, and any analysis on new infrastructures should include not only the coverage of their investment but also the capability to maintain them and equip them with modern technologies (ITS) during their whole life cycle. Currently, resources lack concern space - mostly in Indian cities rather than outside them - and energy. Therefore, these should constitute the constraints on any decisionmaking process regarding high-level transport planning.

An important issue is that the Government has the duty to guarantee free movement to the citizens: the high traffic at certain times of the day in Indian cities is a contradiction to this. Therefore people should have the freedom to choose their most suitable transport means: on foot, by bicycle, by bus, metro, rickshaws, personal cars and so on. Yet this can only be feasible if high level transport plan, in accordance with the above-mentioned goals, is put in place by the Government, before traffic becomes a restriction to personal mobility.

\section{Acknowledgements}

This paper has been adapted from the report Transport and Energy in India Energy used by Indian transport systems and consequent emissions: the need for quantitative analyses (well-to-wheel, lifecycle)" prepared by Politecnico di Torino in March 2013 in the frame of the European Business and Technology Centre in India (EBTC) project [14]. EBTC is a programme co-funded by the European Union and implemented by EUROCHAMBRES, the Association of European Chambers of Commerce and Industry. EBTC's mission is to assist the Business, Science \& Research Community, in Europe and India, to work together towards generating new business opportunities in clean technology transfer \& establishing business relevant cooperation in the field of research, science and technology.

This document has been produced with the financial assistance of the European Union. The contents of this document are the sole responsibility of the EBTC/partner and can under no circumstances be regarded as reflecting the position of the European Union.

\section{References}

[1] Selected Socio-Economic Statistics, October 2011, Ministry of Statistics and Programme Implementation.

[2] Government of India, Annual Report 2011-12, Ministry of Road Transport and Highways.

[3] Government of India, Eleventh and Twelfth Five Year Plan, Ministry of Road Transport and Highways.

[4] "Basic Road Statistics of India", 2004-05 to 2007-05.

[5] Offices of State Transport Commissioners / UT Admin.

[6] SIAM-Society of Indian Automobile Manufacturers (2007). 
[7] Berkeley National Laboratory, Residential and Transport Energy Use in India: Past Trend and Future Outlook, Ernest Orlando Lawrence, January 2009.

[8] International Energy Agency, International Energy Outlook 2011, US, Energy Information Administration Energy Transition for Industry: India and the Global Context.

[9] International Energy Agency, $\mathrm{CO}_{2}$ emissions from fuel combustion, International Energy Agency 2010 edition.

[10] Natural Gas in India, International Energy Agency 2010.

[11] Torchio M.F., Santarelli M.G. Energy, environmental and economic comparison of different powertrain/ fuel options using well-to-wheels assessment, energy and external costs e European market analysis. Energy, 5, 2010.

[12] EcoTransit Website, http://www.ecotransit.org, used on 2012.

[13] Dalla Chiara B., Pinna I., On issues of sustainable transport, International congress - Motor vehicles and Motors 2012, "Sustainable development of automotive industry", 3-5 October Kragujevac, Serbia, ISBN 978-8686663-90-0, 978-86-86663-91-7.

[14] Transport and energy in India energy used by Indian transport systems and consequent emissions: the need for quantitative analyses (well-towheel, lifecycle), 2013, EBTC Report. 